\title{
Supplemental oxygen in surgical patients with COVID-19
}

\author{
Gabriel Enrique Mejía-Terrazas ${ }^{1}$ · Eunice López-Muñoz ${ }^{2}$ (C) \\ Received: 11 August 2020 / Accepted: 21 August 2020 / Published online: 30 August 2020 \\ (c) Japanese Society of Anesthesiologists 2020
}

Keywords Oxygen $\cdot$ Surgery $\cdot$ Regional anesthesia $\cdot$ COVID-19

To the Editor:

We read with great interest the article from Hotta [1]; however, we want to add the following:

In upper limb surgical procedures, when regional anesthesia is administered, the entire surgical team remain in close proximity to the patient's face, with the risk of exposure to atomization of particles $<5 \mu \mathrm{m}$ produced by coughing, sneezing, breathing and speaking, as well as greater dispersion of exhaled air by administration of supplemental oxygen. Also, some particles are small enough to stay in the air for hours, particularly in operating rooms where negative pressure is not available. Similar to that suggested by Mendes et al. [2], we consider that the use of N95 respirators (instead of surgical masks) can be very useful to limit particles spread. The question is, should the N95 respirator be placed on or under the oxygen mask?

Binks et al. [3] proposed placing the surgical mask directly on the patient's nose and mouth and on top of the Hudson-type mask. So, we measured and compared (Wilcoxon Rank-Sum Test) ( Supplementary Figure 1 and

Electronic supplementary material The online version of this article (https://doi.org/10.1007/s00540-020-02850-3) contains supplementary material, which is available to authorized users.

This comment refers to the article available online at https://doi. org/10.1007/s00540-020-02834-3.

Eunice López-Muñoz

astridkaryme2001@yahoo.com.mx

1 Anesthesiology Service, Medica Sur Clinic Foundation, Mexico City, Mexico

2 Medical Research Unit in Reproductive Medicine, Instituto Mexicano del Seguro Social, Unidad Médica de Alta Especialidad Hospital de Gineco Obstetricia No. 4, "Luis Castelazo Ayala”, Río Magdalena 289, 6 Level, Laboratory K, Colonia Tizapan San Ángel, Alcaldía Álvaro Obregón, C.P. 01090 Mexico City, Mexico
Table 1) $\mathrm{FiO}_{2}$ and $\mathrm{ETCO}_{2}$ at three different times, using a carbon dioxide sample line in two situations: First, breathing oxygen at $3 \mathrm{~L} \mathrm{~min}^{-1}$ through a Hudson-type mask with a non-rebreathing reservoir placed on, and second, under an N95 respirator; without finding differences. We believe that the use of N95 respirators under the oxygen masks, should be considered.

\section{Compliance with ethical standards}

Conflict of interest The authors declare that they have no conflict of interest.

\section{References}

1. Hotta K. Regional anesthesia in the time of COVID-19: a minireview. J Anesth. 2020. https://doi.org/10.1007/s00540-020-02834 $-3$.

2. Mendes ABPC, Rodrigues LV, Varandas J, Lages N, Machado H. The role of locoregional anesthesia in the COVID-19 pandemic. Acta Med Port. 2020;33:522-7.

3. Binks AC, Parkinson SM, Sabbouh V. Oxygen: under or over a surgical facemask for COVID-19 patients? Anaesthesia. 2020. https://doi.org/10.1111/anae.15166.

Publisher's Note Springer Nature remains neutral with regard to jurisdictional claims in published maps and institutional affiliations. 